\title{
Prototyping with Raspberry Pi in Healthcare Domain
}

\author{
A Bibliometric Analysis
}

\author{
Hari Kishan Kondaveeti ${ }^{1}$, Sruti Raman ${ }^{2}$, Praveen Raj $^{3}$ \\ Computer Science and Engineering, Vellore Institute of Technology \\ AP, Amaravati, India
}

\begin{abstract}
The objective of this paper is to conduct a bibliometric study on the use of Raspberry $P i$ in the medical field. In the past several decades healthcare advancements have played a major role and Raspberry Pi being the charm with its extensive features and low cost, it is of interest to know whether the development in health care technologies with respect to Raspberry Pi has created an impact or not. A platform known as Biblioshiny has been used to collect statistical information and perform the analysis. A total of $\mathbf{1 5 4}$ journal articles have been collected from PubMed, a free full-text archive of biomedical and life sciences .journal literature at the U.S. National Institutes of Health's National Library of Medicine (NIH/NLM) and analysis has been made on various parameters such as top authors, countries and affiliations etc. The conclusions drawn help us to understand the usage of Raspberry $\mathrm{Pi}$ in the healthcare domain. The Bibliometric Analysis done indicates that there has been an increase in the research over the years and the authors from various countries have been working elaborately indicating that there has been a good amount of usage of Raspberry $\mathrm{Pi}$ in the healthcare domain. Overall, our results demonstrate the trending topics the authors currently working on and collaborations amongst authors and countries. Finally, this paper identifies that there are no motor themes but displays the budding keywords (or the ideas where authors have worked on) in the health care domain emerging with the prototyping of Raspberry $\mathbf{P i}$.
\end{abstract}

Keywords-Information extraction; bibliometric study; prototype; Raspberry Pi; healthcare

\section{INTRODUCTION}

Raspberry Pi is a mini-sized computer, often denoted as credit-card-sized board established by the "Raspberry $\mathrm{Pi}$ Foundation". Originally, Raspberry Pi was developed for students so that they could learn programming which would help them implement innovative projects in various fields [1]. It is essentially a motherboard which has a provision for general purpose input/output pins and enables one to modulate myriad of electronic components. This mini-sized computer comes with its own set of fringe benefits and is known for its affordable price and high computing capability. It runs on various operating systems and is compatible with plenty of programming languages such as $\mathrm{C}, \mathrm{C}++$, Java, Perl and Ruby [2]. It supports various operating systems; it also requires power to boot. However, there are versions of the Raspberry Pi which can boot directly from the network for which file storage system is required [3] Raspberry $\mathrm{Pi}$ is an excellent platform for prototyping (preferably, small scale) [4]. Prototyping ideally deals with validating idea, hypotheses or hardware design. It helps understand vindicate electronic design in an operating system. Prototyping helps weigh the positives and the negatives of the features being implemented in a model. Raspberry $\mathrm{Pi}$ also behaves as an enabler technology [3] The Pi is used to create and develop unconventional projects -widely used in home automation, robot controlling, bots making etc. Due to its high usability, the Pi is used in the evergreen "Healthcare Field" for health monitoring and MRI analysis by making use of the Internet of Things, Smart Devices etc. According to the British Standard Institution (1976), bibliometrics is coined as the 'application of mathematical and statistical methods in the study of the use of documents and publication patterns.' To put the above definition in Layman's terms, bibliometrics can be considered as a procedure which counts the publications and citations relevant to a certain topic. The amalgamation of bibliometrics to science is known as 'Scientometrics'. It is typically defined as the "quantitative study of science and technology" [5].

The most commonly used methods in the field of library and information science are - citation analysis and content analysis. The study of bibliometrics consists of three major bibliometric indicators which are quantity indicators, performance indicators and structural indicators [6].To measure the productiveness of a researcher or research group, the quantity indicator is utilized for evaluating the standard of the journal or the research and the research journal. Structural indicators measure the linkage or the connection amongst various authors, publications etc. [7] Predominantly, the bibliometric study involves the elucidation of activities concerning the topic carried out by researchers, institutions and countries which will help establish trends in research [8] Since, Raspberry Pi is attracting attention in the medical field, this paper attempts to throw light on the popularity of Raspberry Pi over the years in healthcare domain and bring out the trends in various and distinct metrics by conducting the bibliometric analysis.

The rest of the paper is divided into four sections. Section I presents the research methodology to perform the bibliometric analysis. Section II presents the results obtained from the study. Section III shows the conclusions obtained from the study and an acknowledgment. Section IV shows the references which assisted in conducting the study.

\section{Methodology}

The data for the analysis has been collected from the PubMed database, which collects the information from the Medline database compiled by the United States Library of Medicine [9]. The search strategy which was used to collect the information was - "Raspberry Pi". The data was analyzed 
using a web-based Bibliometrix tool in $\mathrm{R}$ called Biblioshiny [10]. The information thus collected has been filtered to obtain precise results. Summary of the findings are as below:

Initially, one hundred and ninety-one (191) articles have been extracted for the analysis. To remove the uncertainties, they are further filtered to document type, "Journal Articles", which fetched one hundred and fifty-four (154) items. These Articles relate to the period between 2013 and 2020 with contributions from six hundred and ninety-seven (697) authors. Conceptual and Social Structure of these articles were analyzed to draw meaningful conclusions.

Table I gives a brief on the data extracted for the period between 2013 and 2020. There are 191 articles as mentioned above, which include those from journals and books numbering 61.249 'Keywords' from these articles are captured for the analysis. 'Keywords' are index terms used by the authors to present the main content of their paper.

TABLE I. MAIN INFORMATION OF DATA COLLECTED

\begin{tabular}{|l|l|}
\hline Description & Results \\
\hline Timespan & $2013: 2020$ \\
\hline Sources (Journals, Books, etc) & 61 \\
\hline Documents & 154 \\
\hline Average years from publication & 1.92 \\
\hline References & 1 \\
\hline Keywords Plus (ID) & 249 \\
\hline Keywords Plus (ID) & 249 \\
\hline Author's Keywords (DE) & 249 \\
\hline Authors & 697 \\
\hline Author Appearances & 733 \\
\hline Authors of single-authored documents & 7 \\
\hline Authors of multi-authored documents & 690 \\
\hline Documents per Author & 0.221 \\
\hline Authors per Document & 4.53 \\
\hline Co-Authors per Documents & 4.76 \\
\hline Collaboration Index & 4.69 \\
\hline
\end{tabular}

Out of contributions from 697 authors in all, 7 are singleauthored documents and the balance 690 documents are multiauthored. Single authored documents are the documents which have been journaled by only one author whereas multiauthored documents are the ones in which there is a collaboration among two or more authors. To assess the overall contribution of an author, the data is further analysed based on 'author appearances'. 'Author appearances' demonstrate whether an author has more than one journal article on his name. In our analysis, considering the count of articles and the frequency of the author's name, seven hundred and thirty-three (733) records have been discovered. Authors per document come to 4.53 , which is calculated by finding the ratio of the total number of authors and documents by them. Likewise, the documents per author come to 0.221 by evaluating the ratio of documents and authors. Co-author per document comes to 4.76 , which is the ratio of the total number of author appearances and documents. The collaboration index is established by correlating the data of authors of multiauthored articles divided by the number of multi-authored articles. [11]. The details are explicitly mentioned in Table I.

\section{RESUltS AND DisCUSSION}

\section{A. Trends in the Number of Articles}

The first publication in the health care domain using Raspberry Pi appeared in the year 2013 with only one article in the entire year. Between 2014 and 2016, the number of articles published on the subject did not cross double-digit. Since 2017, a moderate increase is noticed as shown in Table II. The Annual Scientific Production of the topics is captured in the diagram depicted in Fig. 1, where Y-axis represents the number of articles and $\mathrm{X}$-axis years establishing the relationship of the number of articles to the years. During the initial phase starting from 2013 to 2016, as depicted in Fig. 1, there have been less number of articles in this field but the year 2017 witnessed 23 articles and there has been an increase in the number of articles published since then. In the year 2020, 28 articles have been published. The annual growth is estimated at $60.97 \%$. Annual growth rate establishes the geometric progression ratio that provides a return of constant rate over some time. [12].

TABLE II. NUMBER OF ARTICLES PUBLISHED IN THE CORRESPONDING YEAR

\begin{tabular}{|l|l|}
\hline Year & Articles \\
\hline 2013 & 1 \\
\hline 2014 & 7 \\
\hline 2015 & 7 \\
\hline 2016 & 8 \\
\hline 2017 & 23 \\
\hline 2018 & 31 \\
\hline 2019 & 49 \\
\hline 2020 & 28 \\
\hline
\end{tabular}

Annual Scientific Production

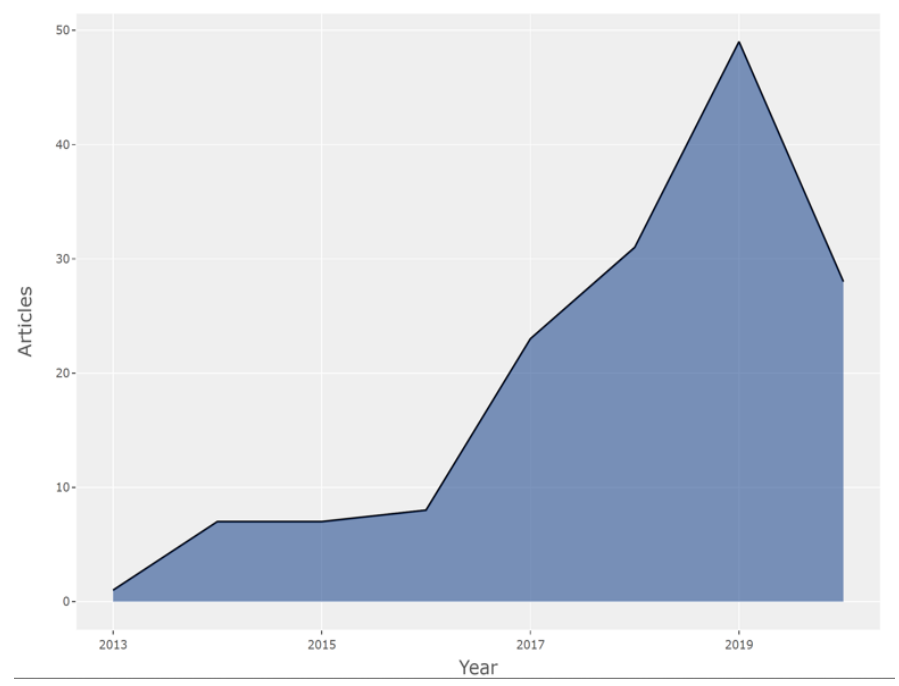

Fig. 1. Trends in the Number of Articles over the Years from 2013-2020. 


\section{B. Top 10 Most Relevant Sources}

A source is essentially is a journal, a book etc. which has issued plenty of documents. This is denoted as sourcing the article/subject of the original author. Table III lists out top 10 sources of articles found on PubMed and the number of times these have been utilized. The observation which can be drawn is that "Sensors" (Basel Switzerland) has been sourced by many articles and "Application in Plant Sciences" has been least sourced.

\section{Documents of Top 3 Authors}

Table IV shows the list of documents journaled by the top three authors. Although 'PLOS one" has several articles under them, the documents written by top five authors are not sourced by "PLOS one". However, multiple authors have worked on the same article.

\section{Top 10 Most Relevant Affiliations}

The affiliations on a research paper imply that the author worked at an institute that oversees the research integrity of the paper published. Affiliations give credibility to the research paper. A study conducted at a reputed University is more respected rather than by the authors affiliated with a university none ever heard of. This explains the reason why researchers from less-known institutions collaborate with researchers of well-known universities.

Table V and the Fig. 2 give an analysis of university affiliations of the authors who published articles on the subject under study. The largest number of affiliations are to the University of British Columbia with 25 articles which are represented by a dark shade of blue in the Fig. 2. In the Fig. 2, the $\mathrm{X}$-axis denotes the number of articles and the $\mathrm{Y}$-axis denotes the name of the affiliation. The intensity of the color decreases as we go down the graph indicating the decrease in the frequency of articles. Kinsmen Laboratory of Neurological research has the least number of articles affiliated. However, the other universities, to cite a few, Tucson, University of Alberta, etc. have a good number of papers that are affiliated.

TABLE III. A TABULAR REPRESENTATION OF THE SOURCES AND CORRESPONDING NUMBER OF ARTICLES

\begin{tabular}{|l|l|}
\hline Sources & Articles \\
\hline Sensors (Basel Switzerland) & 68 \\
\hline PLOS one & 68 \\
\hline $\begin{array}{l}\text { Conference proceedings - Annual International } \\
\text { Conference of the IEEE, Engineering in Medicine and } \\
\text { Biology Society }\end{array}$ & 7 \\
\hline Review of scientific instruments & 6 \\
\hline Journal of Neuroscience methods & 5 \\
\hline Biosensors and Bioelectronics & 3 \\
\hline Journal of medical systems & 3 \\
\hline Plant methods & 3 \\
\hline PLOS Biology & 3 \\
\hline Applications in plant sciences & 2 \\
\hline
\end{tabular}

www.ijacsa.thesai.org
TABLE IV. TOP AUTHORS AND THE CITATION OF THEIR CORRESPONDING ARTICLES

\begin{tabular}{|l|l|}
\hline Author & Citation \\
\hline Murphy Th & {$[18],[19],[20],[21],[22]$} \\
\hline Barker D & {$[23],[24],[25],[26]$} \\
\hline Boyd Jed & {$[18],[19],[22]$} \\
\hline
\end{tabular}

TABLE V. TOP 10 AFFILIATIONS AND THE NUMBER OF DOCUMENTS AFFILIATED

\begin{tabular}{|l|l|}
\hline Affiliations & Articles \\
\hline University of British Columbia & 25 \\
\hline Zhejiang University & 17 \\
\hline Tucson & 16 \\
\hline University of Science and Technology of China & 16 \\
\hline Universidad Carlos III De Madrid & 15 \\
\hline University of Alberta & 15 \\
\hline University of Tubingen & 13 \\
\hline The University of Sheffield & 12 \\
\hline University of California & 12 \\
\hline Kinsmen Laboratory of Neurological Research & 11 \\
\hline
\end{tabular}



Fig. 2. A Graphical Representation of Top-10 Affiliations and the Number of Documents Affiliated.

\section{E. Top 10 Corresponding Author's Countries}

The leading authors of the articles belong to China, USA, France and Korea; most of the authors are from China and the USA as shown in the graph (Fig. 3). The X-axis represents the number of documents and the Y-axis represents the countries. SCP is the abbreviation for Single Country Publication and MCP is an abbreviation for Multiple Countries Publication. It can be concluded that there are no documents where a coauthor from a different country is working on in the dataset under analysis.

\section{F. Top-10 Country Specific Production}

Country specific production gives us an insight into the number of journal articles produced in a specific country. From the Table VI, it can be observed that the USA tops the list by producing 117 articles over the years and the UK appears at the bottom by producing the least with 26 articles. 




Fig. 3. A Graphical Diagram Representing the Top 10 Author's Countries.

TABLE VI. TOP 10 COUNTRIES WITH THE HigheST NUMBER OF PRODUCTIONS

\begin{tabular}{|l|l|}
\hline Terms & Frequency \\
\hline system & 29 \\
\hline raspberry & 22 \\
\hline low-cost & 21 \\
\hline monitoring & 19 \\
\hline based & 18 \\
\hline pi & 18 \\
\hline open & 13 \\
\hline platform & 13 \\
\hline data & 12 \\
\hline
\end{tabular}

G. Frequently used Words - Author's Keywords, Title, Abstract

A word cloud is a pictorial representation of the collection of words related to a specific parameter, be it author's keywords or title or abstract. The cloud is essentially designed such a way that the word with higher importance or most reoccurring is typically depicted in a bigger font and the words with less frequency gradually decrease in size. Various data transformations can be used to understand the occurrence of words. Since dataset under observation is not humongous, the analysis is confined to the measure of "frequency". Other options such as log, square root transformations are available which will give the preview of the word cloud, based on the scaled transformation applied to the data [13].

1) Author's keywords: Author's keywords, as mentioned earlier is a list of terms which relate to the main topic of the author's paper. Fig. 4 captures, the terms and Table VII gives the details about the word and their frequency. An interesting observation made in the analysis is that the most commonly used words by the authors are 'humans', 'software', 'animals', 'female' etc. The frequency of usage of the word 'humans' was 48 times, which gives a conclusion that the application of Raspberry Pi has been essentially used to the benefit of human beings.
2) Most Commonly used words in titles: It is also analyzed whether the term Raspberry Pi appears in the title and the abstract of the articles produced. From Table VIII and the Fig. 5, it is interpreted that the word "system" has the highest frequency which can be seen from the cloud of words such as.

- Prototyping of Raspberry pi is used.

- Integration of IoT.

- Open-source platform.

- Working on low cost, smart, robust systems.

- Applications of the raspberry pi for monitoring purposes.

3) Most commonly used words in abstract: "System" and "data" are the two terms with the highest frequencies. It is quite evident that most of the terms in the title and the abstract have been repetitive. 'An amusing observation here is that the usage of the term Raspberry $\mathrm{Pi}$ is more when compared to its usage to the title and author's keywords. The occurrence of the terms can be seen in Table IX and Fig. 6.



Fig. 4. Word cloud depicting the most Common Author's Keywords.

TABLE VII. MOST FREQUENT TERMS AND ITS OCCURRENCE IN AUTHOR'S KEYWORDS

\begin{tabular}{|l|l|}
\hline Region & Freq \\
\hline USA & 151 \\
\hline CHINA & 82 \\
\hline SPAIN & 81 \\
\hline CANADA & 67 \\
\hline GERMANY & 39 \\
\hline BRAZIL & 38 \\
\hline ITALY & 37 \\
\hline SOUTH KOREA & 31 \\
\hline MEXICO & 30 \\
\hline UK & 26 \\
\hline
\end{tabular}


TABLE VIII. MOST FREQUENT TERMS AND ITS OCCURRENCE IN TITLES

\begin{tabular}{|l|l|}
\hline Terms & Frequency \\
\hline humans & 48 \\
\hline software & 20 \\
\hline animals & 17 \\
\hline female & 13 \\
\hline algorithms & 12 \\
\hline equipment design & 12 \\
\hline male & 12 \\
\hline computers & 7 \\
\hline image-processing computer-assisted & 7 \\
\hline internet & 7 \\
\hline
\end{tabular}

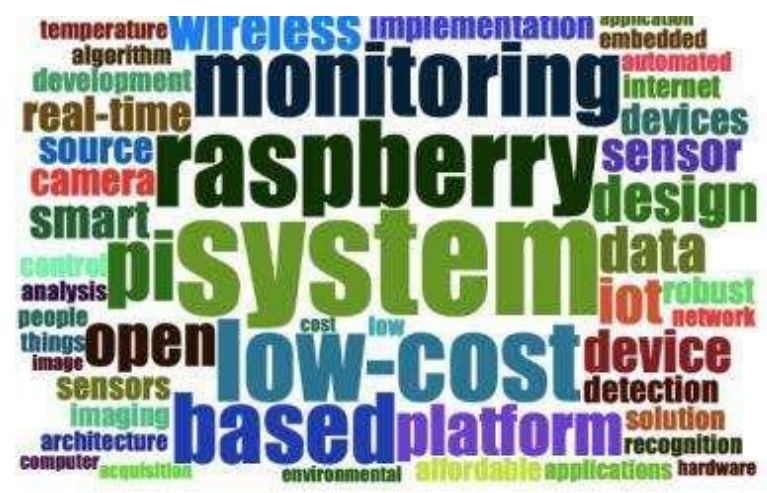

Fig. 5. Word cloud depicting the Most Common Words Found in titles.

TABLE IX. MOST FREQUENT TERMS AND ITS OCCURRENCE IN ABSTRACT

\begin{tabular}{|l|l|}
\hline Terms & Frequency \\
\hline system & 209 \\
\hline data & 159 \\
\hline pi & 153 \\
\hline raspberry & 153 \\
\hline device & 89 \\
\hline based & 86 \\
\hline proposed & 82 \\
\hline low-cost & 77 \\
\hline devices & 76 \\
\hline sensor & 71 \\
\hline
\end{tabular}

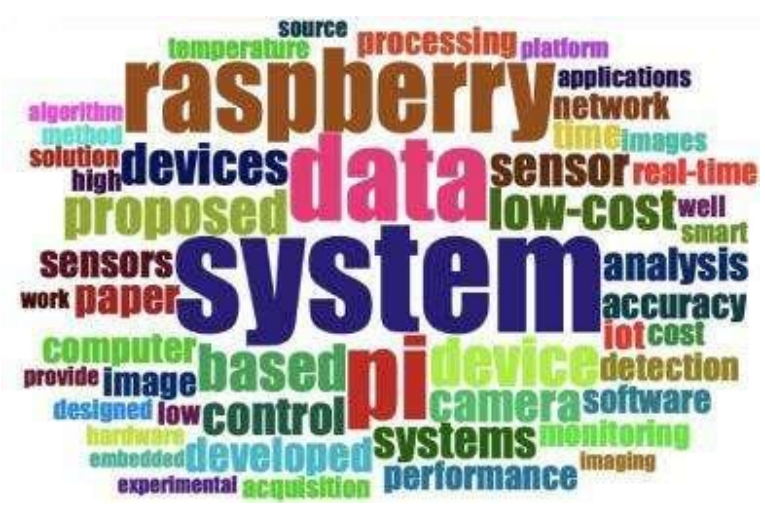

Fig. 6. Word cloud Depicting the Most Common Words Found in the Abstract.

\section{H. Graphical Analysis}

Biblioshiny platform has a graphical analysis tool known as "Three-Field-Plot" which helps in determining the relationship between three metrics in a graph. It works on the principle of the Sankey diagram. Three field plot is divided into 3 fields namely-

- Middle field

- Leftfield

- Right field

Sankey diagram consists of boxes; the size and the dimensions of the box are directly proportional to the frequency or the count of the entered metrics.

For the first analysis three fields viz., Middle: Keyword, Left: Author, Right: Sources are considered confining to top 10 interactions amongst them.

Fig. 7 re-establishes that "Human" is the most commonly used keyword and has been frequently used by most of the sources such as "Sensors (Basel, Switzerland)". The authors, to name a few, Sahoo $\mathrm{n}$ and Lin hw have been working on projects which use the keywords (topics) such as 'humans', 'user computer interface', 'equipment design' etc.

For the second analysis the three fields viz., Middle: Keyword, Left: Country, Right: Sources are considered restricting again to top 10 interactions amongst them.

The graph (Fig. 8) depicts that the highest production of articles is from the country - "China" and the authors have utilized the topics/keywords such as 'keywords', 'algorithms', 'image processing', 'computer-assisted', 'equipment design' and 'user computer interface'. Interestingly, the most frequently used keyword - "Humans" has been used in the journal articles produced by all the countries present in the graph (Spain, China, France, Korea, Mexico, USA, Italy, Germany, Canada). It has been sourced by all except for journal of neuroscience methods. We can also see that that 'Sensors' (Basel, Switzerland) has been sourced by all the keywords. Table $\mathrm{X}$ lists out the country and the topics the countries have been working on. By analyzing the width between the country and the keyword, Table XI is prepared to give an insight into the topic(s) the respective countries are specifically working on.

The third graphical analysis involves the three fields, viz., Middle: Author, Left: Affiliations, Right: keywords; restricting to top 10 interactions. The graph (Fig. 9) represents the keywords used by the author and the university the author has been affiliated to.

The fourth graphical analysis (Fig. 10) gives us an insight into the author's country. Considering the three fields viz., Middle: Author, Left: Countries, Right: Affiliations. The relationship between the three is established.

The fifth graphical analysis (Fig. 11) uses Middle: Affiliation, Left: Authors, Right: Countries, restricting the number of items to 24 to find out the affiliation of later items. 


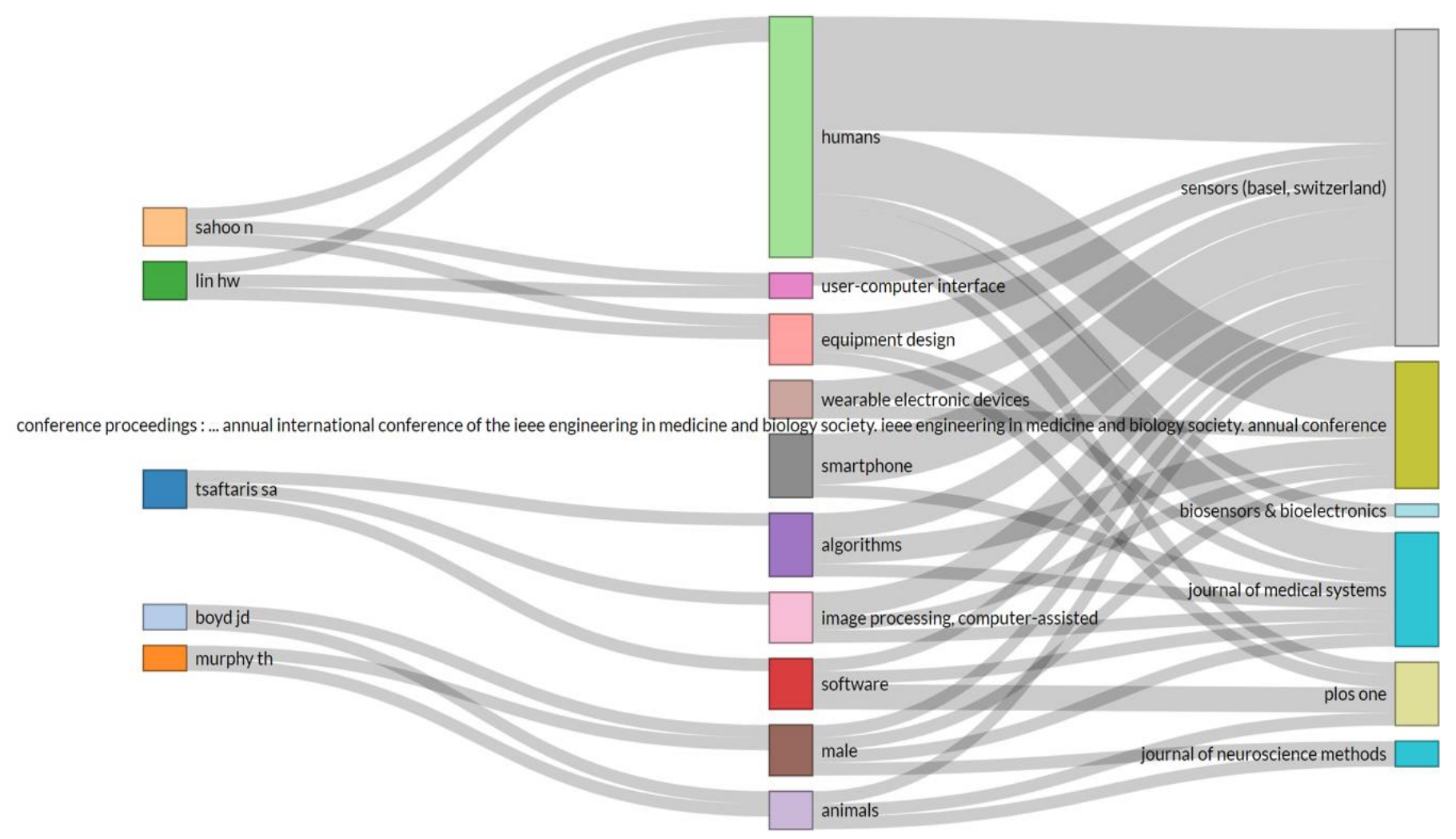

Fig. 7. Three Plot Diagram Representing the Relationship among Keywords, Authors and Sources.

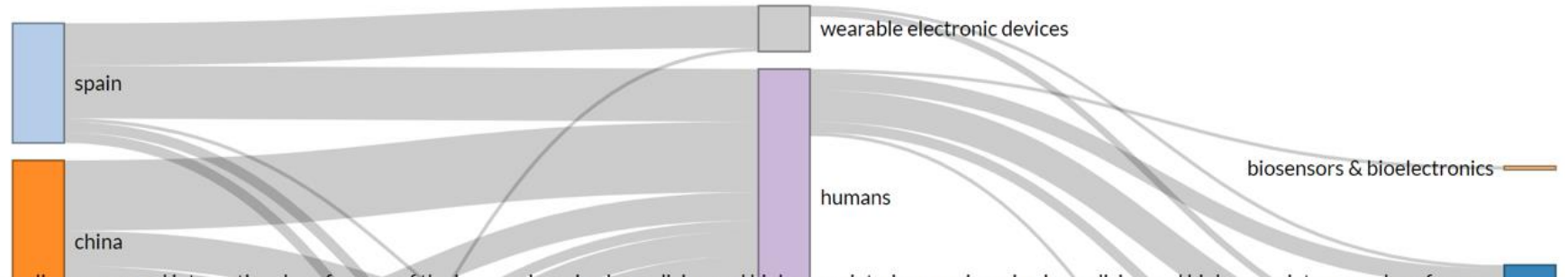

conference proceedings :... annual international conference of the ieee engineering in medicine and biology society. ieee engineering in medicine and biology society. annual conference



Fig. 8. Three Plot Diagram Representing the Relationship among Keywords, Country and Sources. 
TABLE X. LIST OF COUNTRIES AND THE RELATED CORRESPONDING TOPICS

\begin{tabular}{|l|l|}
\hline Country & Topic(s) \\
\hline Spain & $\begin{array}{l}\text { The wearable electronic device, humans, image processing- } \\
\text { computer assisted, smartphone, male }\end{array}$ \\
\hline France & $\begin{array}{l}\text { Humans, algorithms, image processing- computer-assisted } \\
\text { equipment design, user computer interface }\end{array}$ \\
\hline Korea & Humans, image, processing, computer-assisted, smartphone \\
\hline Mexico & Humans, image processing-computer assisted \\
\hline USA & Humans, smartphone, user computer interface, software \\
\hline Italy & $\begin{array}{l}\text { The wearable electronic device, humans, algorithms, image } \\
\text { processing, computer-assisted, male, equipment design, } \\
\text { software }\end{array}$ \\
\hline Germany & $\begin{array}{l}\text { Humans, smartphones, user computer interface, software } \\
\text { animals }\end{array}$ \\
\hline Canada & \begin{tabular}{l} 
Humans, smartphones, male, software, animals \\
\hline
\end{tabular} \\
\hline
\end{tabular}

TABLE XI. LIST OF COUNTRIES AND YHE CORRESPONDING MAJOR TOPICS

\begin{tabular}{|l|l|}
\hline Country & Topic(s) \\
\hline Spain & Wearable electronic device, humans \\
\hline China & $\begin{array}{l}\text { Humans, algorithms } \\
\text { image processing, computer-assisted }\end{array}$ \\
\hline France & Humans, image processing, computer-assisted, smartphone \\
\hline Korea & Humans, algorithms \\
\hline Mexico & Humans, image processing, computer-assisted \\
\hline USA & Humans, smartphone, software \\
\hline Italy & $\begin{array}{l}\text { Algorithms, image processing, computer-assisted, equipment } \\
\text { design, software }\end{array}$ \\
\hline Germany & User computer interface, animals \\
\hline Canada & Software, animals \\
\hline
\end{tabular}

By analyzing the three graphs (Fig. 9, Fig. 10, Fig. 11), the most common keywords used by the author, the paper's affiliation and the country in which the author has published the journal article can be identified. The keywords for authors whose papers were published in Korea are not available, however, it can be noticed as mentioned in the Table $\mathrm{X}$ that Korea has essentially worked on 'Humans' and 'algorithms'. So, for the current analysis, these keywords have been added against their names. The tabulated chart can be seen in Table XII. Table XII gives the impression that the most popular topics on which the top authors are working relate to humans and animals. To analyze whether the topic on which the authors are working on is a trending topic or a general topic with scope for further development, network analysis is conducted.

\section{Knowledge Synthesis}

Knowledge synthesis is made up of three fragments which are.
- Conceptual structure
- Intellectual structure

\section{- Social structure}

The conceptual structure involves network analysis of the co-words' networks, which is ideally studying and analyzing of graphs depicting a collection of words appearing together.

To identify the evolution of themes and infer the topics, the thematic map is used. A graph has nodes also known as vertices which are linked by lines or edges.

The colors represent the clusters to which the words belong to as shown in Fig. 12. The parameter used for constructing the graph is the author's 'keywords'. Salton's cosine, Jaccard's Index and Association Strength [14] are used for measuring the co-occurrence and Louvain algorithm for clustering [15].

The map as shown in Fig. 12 gives a visual representation of the most co-occurring words and it is observed that the vertex representing "Humans" has highly reoccurred. The strength of the edges is proportional to the co-occurrences. The link between "Humans" and "image processing", "computer-based" is much stronger than the other edges inferring that the Raspberry $\mathrm{Pi}$ is being used or studied concerning applications which have the ability of image processing.

\section{J. Thematic Evolution - A Longitudinal Thematic Map Analysis}

A thematic map is used for visualizing a certain topic and the concept used in the paper by choosing "author's keywords". The map is divided into four plots or quadrants viz., Upper left plot: highly developed and isolated themes, Upper right plot: Motor themes; Lower left plot: emerging or declining themes; Lower right plot: Basic and transversal themes. Each quadrant is depicted as a Thematic map [16] As shown in the map (Fig. 13) each bubble depicts a network cluster and the word which is being represented in the bubble has the highest occurrence value. The position of the bubbles is according to the Centrality and Density which are captured in $\mathrm{X}$ and $\mathrm{Y}$ axes, respectively [17].

Centrality helps to measure the degree of interaction amongst the myriad clusters present in the graph. It helps in estimating the importance of the theme in the entire research area. Density estimates the internal strength of the cluster, in other words, it is the measure of the theme's development in the entire research.

The purpose of using thematic evolution for the analysis is to discover if there are any topics which have emerged into any other quadrants and more so to understand the topic's evolution over some time. The span of years is divided into two parts, and the cutting point emerged as 1. (2013-2017, 2018-2020).

Time Slice-1: The conjecture made from the Fig. 13 is that "wireless technology/instrumentation" is a motor theme and was a Central Point for conducting research studies concerning Raspberry Pi.

The second observation of the analysis is that the bubbles referring to" humans" is in emerging or declining themes as the frequency of words in the cluster are in the declining zone. 


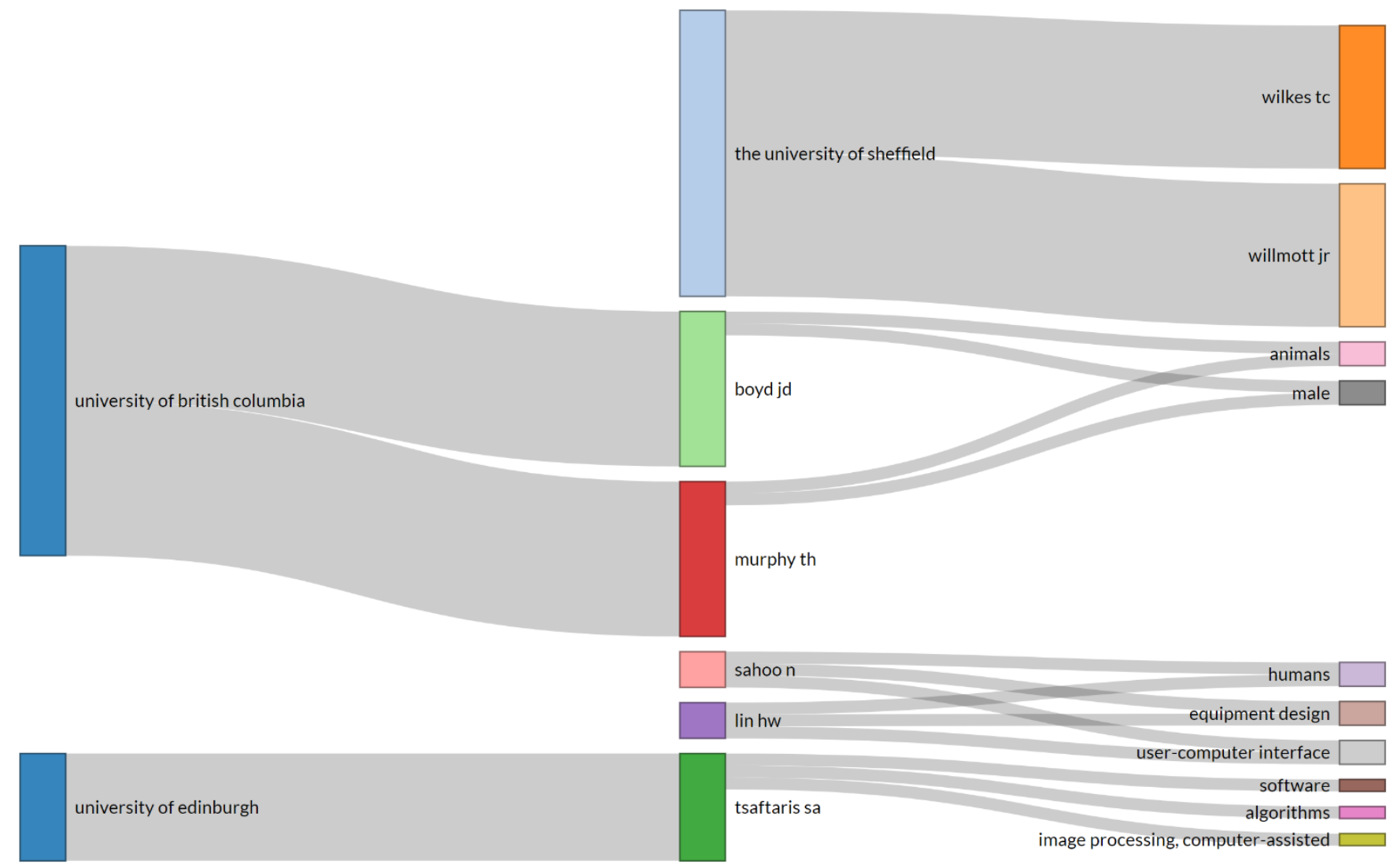

Fig. 9. Three Plot Diagram Representing the Relationship among Authors, Affiliations and Keywords.

\begin{tabular}{l|l|}
\hline korea & hang I $\square$ \\
\hline france & kim dh \\
china & sahoon \\
\hline lim hw \\
\hline
\end{tabular}
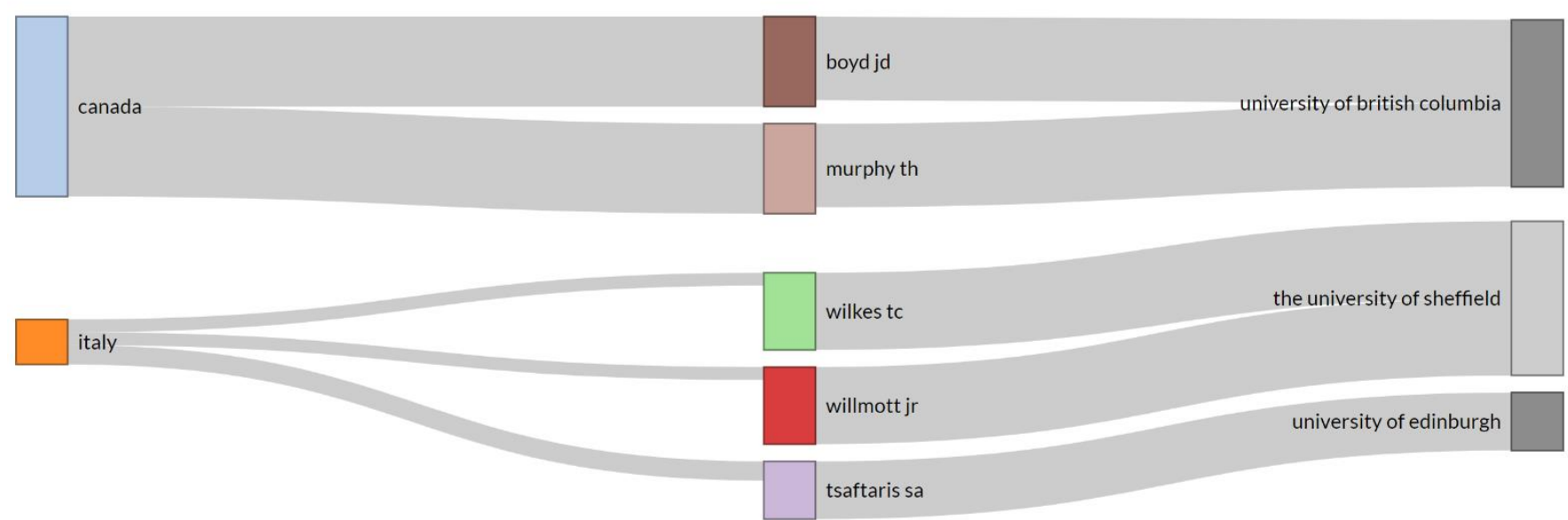

Fig. 10. Three Plot Diagram Representing the Relationship among Authors, Countries and Affiliation. 




Fig. 11. Three Plot Diagram Representing the Relationship among Affiliations, Authors and Countries.

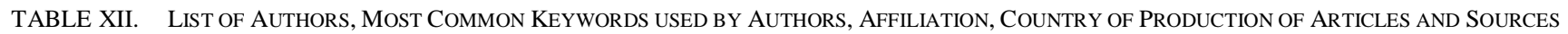

\begin{tabular}{|l|l|l|l|l|}
\hline Author & Keywords used by the author & Affiliation & Country & Sources \\
\hline Wilkes Tc & unavailable & The University of Sheffield & Italy & Sensors (Basel, Switzerland) \\
\hline Willmott Jr & unavailable & The University of Sheffield & Italy & Sensors (Basel, Switzerland) \\
\hline Boyd Jd & Animals, male & University of British Columbia & Canada & Journal of Neuroscience Methods \\
\hline Murphy Th & Animals, male & University of British Columbia & Canada & Journal of Neuroscience Methods \\
\hline Sahoo n & $\begin{array}{l}\text { Humans, equipment design, user } \\
\text { computer interface }\end{array}$ & Unavailable & China & Sensors (Basel, Switzerland) \\
\hline Lin Hw & $\begin{array}{l}\text { Humans, equipment design, user } \\
\text { computer interface }\end{array}$ & Unavailable & China & Sensors (Basel, Switzerland) \\
\hline Tsaftaris Sa & $\begin{array}{l}\text { Software, algorithms, image } \\
\text { processing, computer-assisted }\end{array}$ & University of Edinburgh & Italy & Plant methods. \\
\hline Hang 1 & Humans, algorithms & Jeju National University & Korea & Sensors (Basel, Switzerland) \\
\hline Kim DH & Humans, algorithms & Jeju National University & Korea & Sensors (Basel, Switzerland) \\
\hline Kim SW & Unavailable & Unavailable & Korea, France & Sensors (Basel, Switzerland) \\
\hline
\end{tabular}

'Software', 'behaviour,' and 'animal/physiology' belong to the basic and transversal themes which establish that those were the general topics during the years 2013-2017. It is also observed that 'equipment design' is right in the middle of the map, covering a tiny portion from all the quadrants.

Time Slice-2: In the Fig. 14, plenty of new keywords can be noticed in the graph and 'humans' has its locomotion from emerging/declining topics to general and transversal themes whereas 'wireless technology' or 'instrumentation' is no more a "motor theme" which insinuates that there are new topics which have merged or have been split into individual topics.

The Fig. 15 gives distribution and diversity of topics (author's keywords) over the years in the given time slice. In the first slice, all the topics have started uniquely and topics such as 'humans', 'wireless technology/instrumentation' and 'software' have diverged into various fields. However, the whole of behavior, 'animal/physiology' has shifted to 'female' and 'animals' has shifted into; automation', 'laboratory/instrumentation'. The keywords popular in the time slice between 2018-2020 are 'humans', 'automation', 'laboratory/instrumentation', 'female', 'software', 'anticoagulants', 'equipment design', 'wearable electronic devices' and 'algorithms'.

Fig. 16 captures the clusters from 2013-2020 by combining the occurrences of various topics and keywords in the thematic map. 


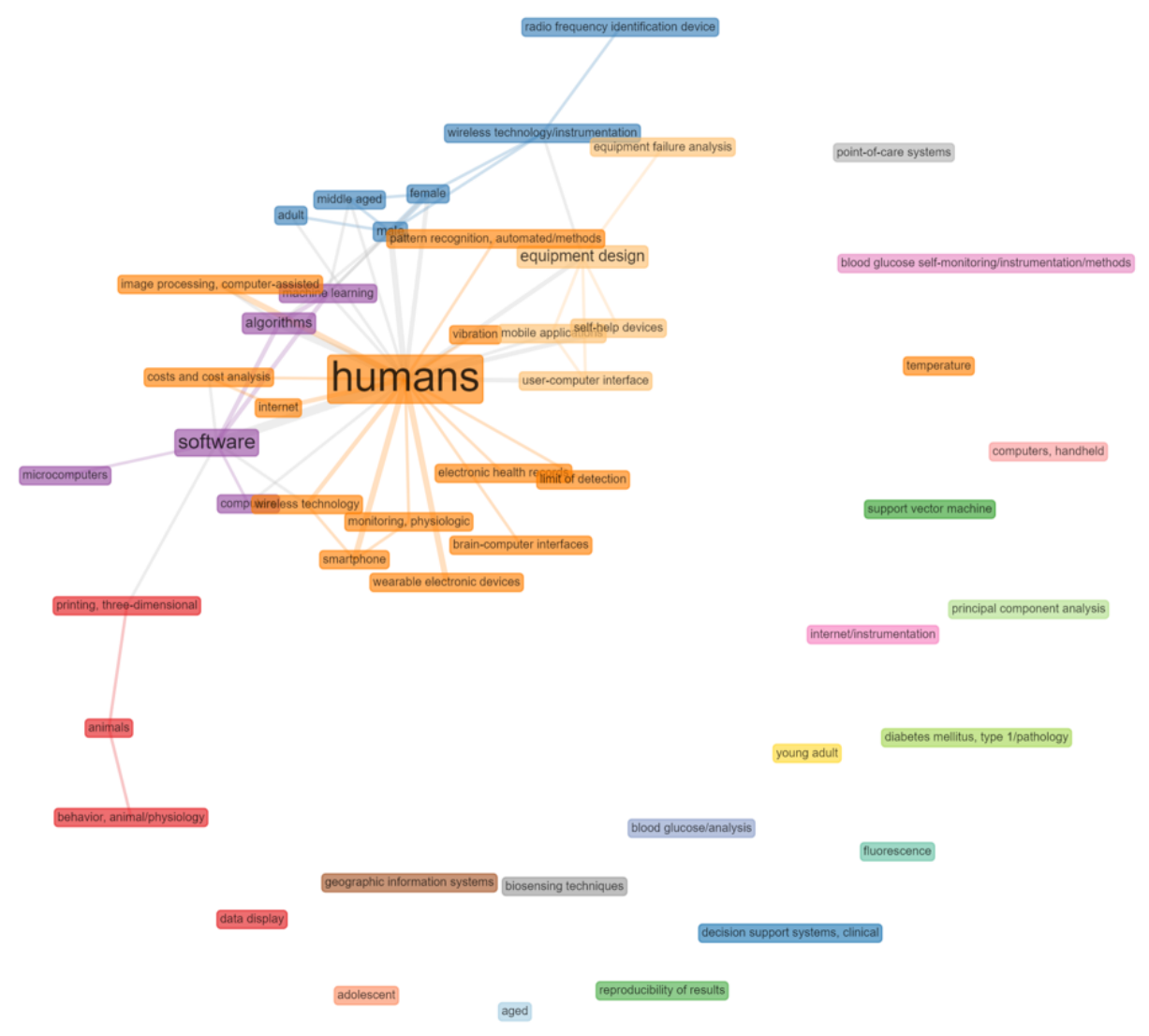

Fig. 12. A Graphical Representation of a Network of the most co-Occurring Words in all the Articles.



\section{Centrality}

Fig. 13. Strategic Diagram Representing the Author's Keywords in Time Slice -1 . 


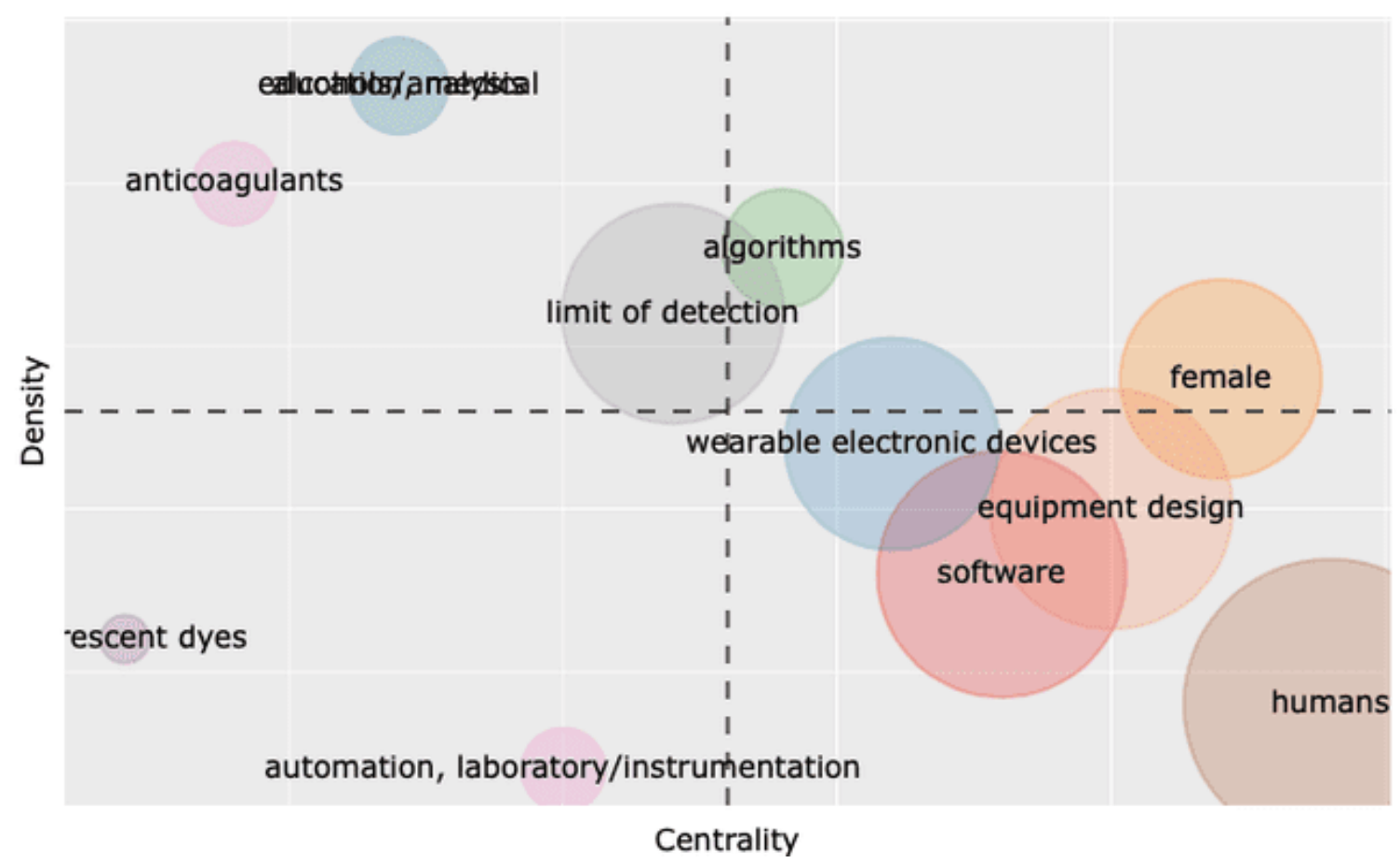

Fig. 14. Strategic Diagram Representing the Evolution of the Author's Keywords in Time Slice -2.

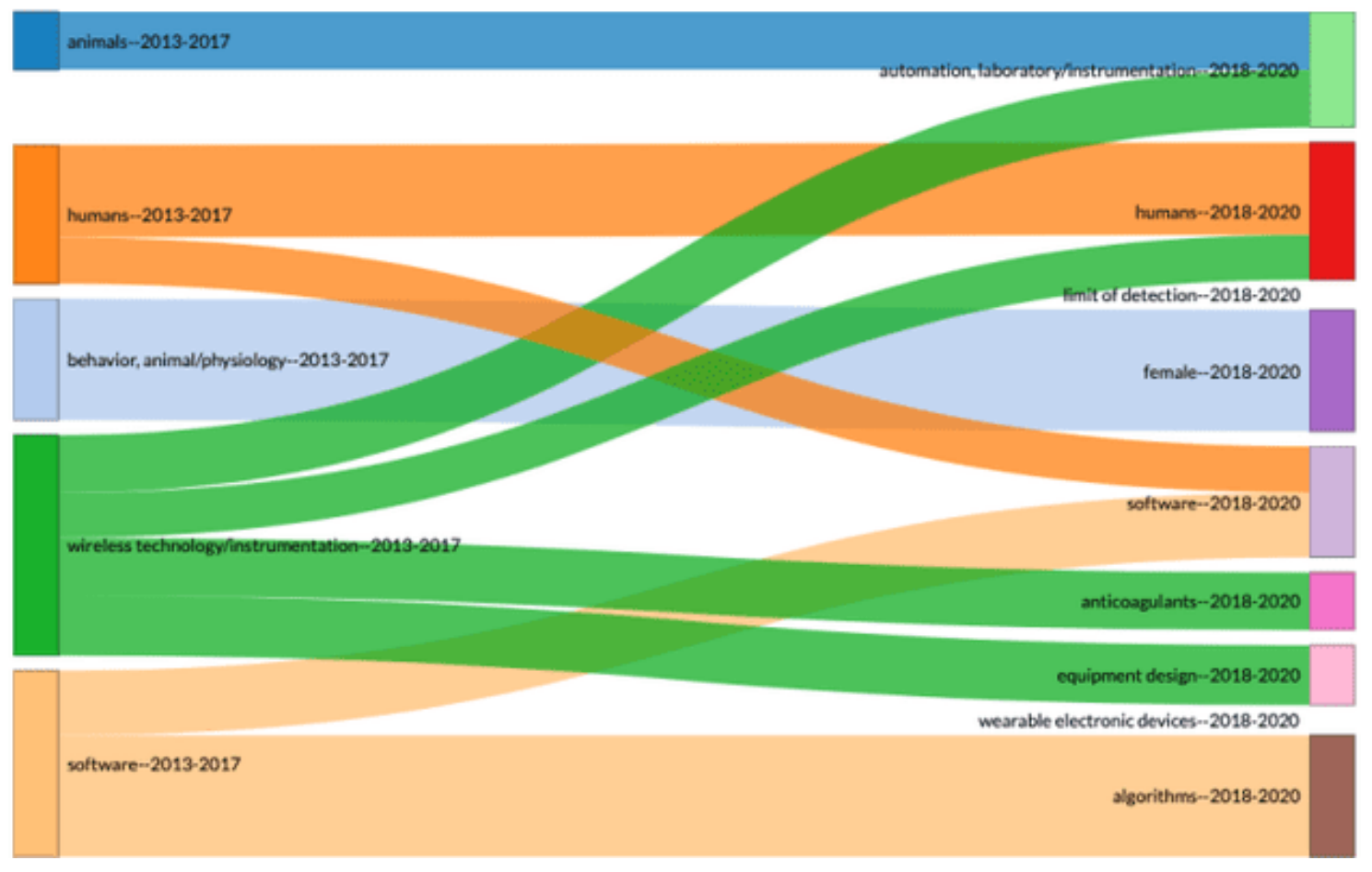

Fig. 15. 2-Plot Diagram for the Evolution of Author's Keywords over the Year. 


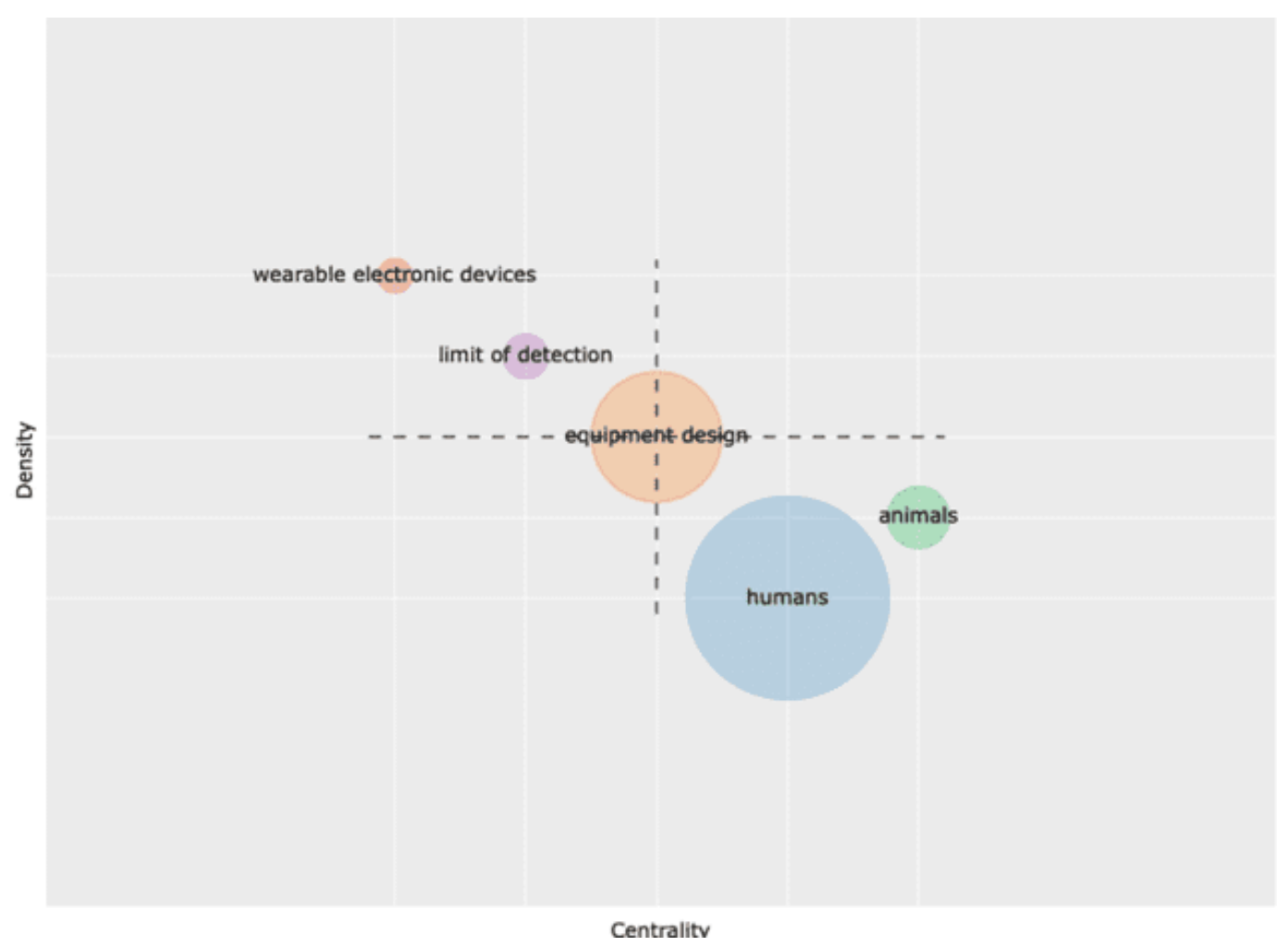

Fig. 16. Overall Strategic Diagram for Author's Keywords from 2013-2020.

It can be noticed that the bubble-"human", belongs to the basic and transversal themes indicating that the bubble has shifted its position from one plot to the other, which can be seen in the evolution in the latter part. Two of the terms which are highly recurring in the 'humans bubble' are 'software' and 'algorithm' which reflects that dynamic problem solving requires the usage of algorithms. In the 'animals bubble', the recurring terms are 'physiology' and 'three dimensional/printing'. The analogy here seems to be the development of a health monitoring system or something similar which requires 3D printing for various parts and physiological parameters for monitoring the health status of individuals. It is noticed that there is no particular bubble positioned in the 'motor theme plot' signaling that there are no mainstream fields in the research topic. 'Wearable electronic devices' and 'limit of detection' do not hold much of place in the research field since they lie in the upper left quadrant. However, 'humans' and 'animals bubble' are vital in the research study but it could be interpreted that they are not yet evolved fully or the researchers are still working on their development. They are the basic general topics with good scope for further development. Intellectual Structure involves citation analysis, which is not attempted in the paper due to the current restriction in accessing the citation details from PubMed.

\section{K. Social Structure}

Social structure deals with the relationship between countries and authors in the research area.

1) Country collaboration: Fig. 17 depicts a list of countries arranged randomly, with each color of the node representing a unique cluster. Countries which have collaborated or are collaborating are categorized in the clusters joined through links. It is noticed that Spain has collaborations with both Mexico and USA; Germany and Switzerland also appear in the collaborated list. The rest of the countries remain independent. The observations are recorded in Table XIII.

2) Co-author collaboration: Co-author collaboration helps us in perceiving a pictorial representation of collaboration amongst authors. The same understanding of the graph applies here which is each unique color represents a cluster and the authors which are working together are connected by links. From the Fig. 18, it is observed that there are 39 clusters in all, out of which there are 4 clusters which represent the collaboration of authors which has been recorded in Table XIV. 


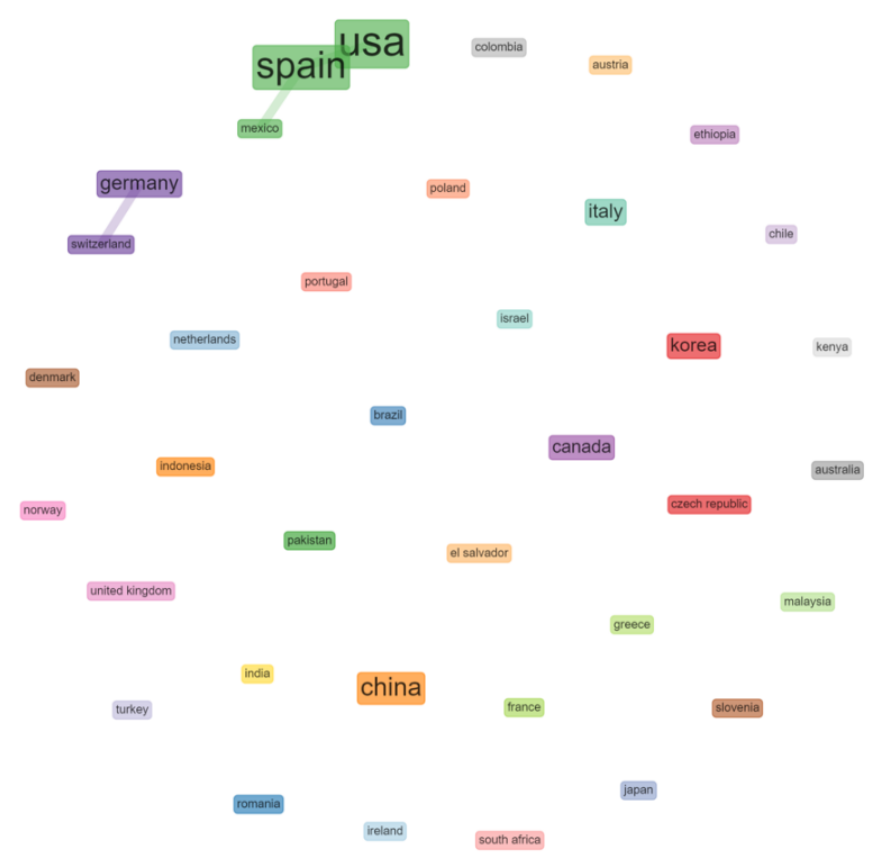

Fig. 17. A Graphical Representation of a Network of Countries which have Collaborated.

TABLE XIII. LIST OF COUNTRIES THAT COLLABORATED

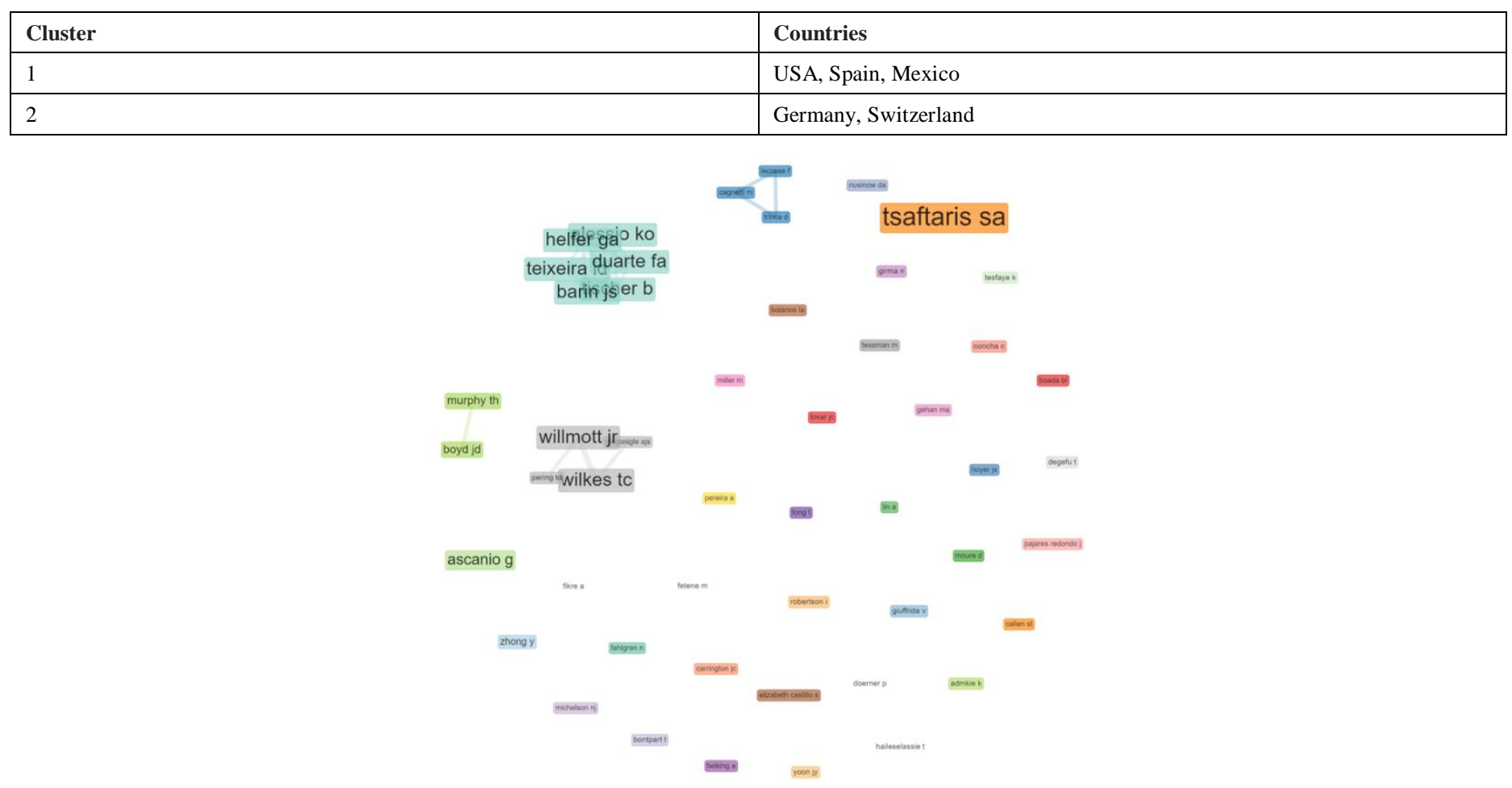

Fig. 18. A Graphical Representation of a Network Describing the Collaboration amongst Authors.

TABLE XIV. LIST OF AUtHORS THAT HAVE COLLABORATED

\begin{tabular}{|l|l|}
\hline Cluster & Authors \\
\hline 1 & Boyd did, Murphy th \\
\hline 2 & Wilkes tc, Willott jr, Pering td, Mcgonigle ajs \\
\hline 3 & Leccese F, Trinca D, Cagnetti M \\
\hline 4 & Alessio Ko, Tischer B, Teixeria id, Duarte fa, Helfer ga, Barin js \\
\hline
\end{tabular}




\section{CONCLUSION}

The analysis leads to the following conclusion:

- A total of 154 articles have been published from 20132020 in the health-care field using Raspberry Pi, with the year 2019 having the highest number of journal articles published.

- The United States of America leads the table with the highest number of specific country production and most of the authors working on the topic belong to China with less representation from Korea.

- University of British Columbia, Canada has the greatest number of affiliations to the topic. Considering all the data and analyzing the graphs with various parameters, a table (Table XII) has been constructed which represents the most common keywords used by the top authors and the country from which the paper has been published and its corresponding source.

- The most trending keyword by the top authors is "Humans." On performing knowledge analysis (conceptual structure - discovering major themes and trends), the graphs insinuate that there is no "Motor Theme" as yet in the healthcare domain. On the contrary, a lot of research work is being done on 'Humans' and 'animals' in this field, for instance, 'Health monitoring system for animals and humans.

- By making use of Social Structure which per se helps us to identify the relationships between authors and countries who have collaborated, the results deduce that there are a couple of authors who are working in harmony towards this budding topic in the research field and the USA, Mexico, Spain; Switzerland and Germany are the countries which are working collaboratively in this research field.

Despite the limitations of not conducting intellectual structure analysis because of restriction of citation details from PubMed, the findings are valuable in light of a strong basic analysis for future research. Thematic analysis has been a game-changer in our trend analysis.Broadly translated, our findings indicate that there is no motor theme emerging in the present context but more research in the upcoming years may alter the position. However the present findings do confirm that there has been a progress in affairs which involve amalgamation of Raspberry Pi along with wearable electronic devices, various algorithms, image processing techniques, etc.

\section{FUTURE WORK}

Future studies could fruitfully explore more domains on the applicative trends of Raspberry Pi in healthcare. Few recommendations for future research are given.

- Enhancements in the current technologies with respect to the $\mathrm{Pi}$ in order to boost compatibility, connectivity and productivity.

- Security, privacy, legal issues which have to be tackled while using the same.
Looking forward, further attempts could prove quite beneficial to the literature.

\section{ACKNOWLEDGMENT}

We would like to express our special thanks of gratitude to our Prof. Hari Kishan Kondaveeti for his valuable and constructive suggestions during the planning and development of this research. He has been a constant support for us in bringing the best out of us and shaping the paper with his immense knowledge and patience.

\section{REFERENCES}

[1] R. B. Kent, Science and Computing with Raspberry Pi, IOP Concise Physics, 2018.

[2] P. Sachdeva and S. Katchi, "A Review Paper on Raspberry Pi," International Journal of Current Engineering and Technology, 2014.

[3] J., , S. Johnston and J. ,. S. Cox, Raspberry Pi Technology, 2018.

[4] M. Saari, b. M. ,. A. Baharudin and S. Hyrynsalmi, Survey of Prototyping Solutions Utilizing Raspberry Pi, 2017.

[5] V. Raan, "In matters of quantitative studies of science the fault of theorists is offering too little and asking too much," Scientometrics, vol. 43, p. 129-139, 1998.

[6] J. Lundberg, "Bibiliometrics as a research assessment tool : impact beyond the impact factor," 2006.

[7] V. Durieux and P. Gevenois, " Bibliometric Indicators: Quality Measurements of Scientific Publication," Radiology, vol. 255, no. 2, pp. 342-51, 2010.

[8] L. L. Li, G. Ding, N. Feng, M. H. Wang and Y. S. Ho, "Global stem cell research trend: Bibliometric analysis as a tool for mapping of trends from 1991 to 2006," Scientometrics, vol. 80, pp. 39-58, 2009.

[9] F. Fatehi, G. Leonard and W. Richard, "How to improve your PubMed/MEDLINE searches: 1. background and basic searching," Journal of telemedicine and telecare, 2013.

[10] M. Aria, "bibliometrix: An R-tool for comprehensive science mapping analysis," Journal of Infometrics, 2017.

[11] B. Elango and P. Rajendran, "Authorship trends and collaboration pattern in the marine sciences literature : a scientometric study.," International Journal of Information Dissemination and Technology, 2, pp. 166-169, 2012.

[12] W. contributors, "Compound annual growth rate," 28 March 2020. [Online]. Available: https://en.wikipedia.org/w/index.php?title=Compound_annual_growth_r ate \&oldid $=947842856$.

[13] J. H. McDonald, Handbook of Biological Statistics, Sparkly house publishing, 2009.

[14] L. W. Nees Jan van Eck, "How to Normalize Co-Occurrence Data? An Analysis of Some Well-Known Similarity Measure," Journal of the American Society for Information science and Technology , 2009.

[15] A. L. a. S. Fortunato, "Community detection algorithms : a comparative analysis," Physical review, 2009.

[16] M. J. Cobo, G. ,. A. Lopez - Herrera, E. Herrera - Viedma and F. Herrera, "An approach for detecting, quantifying, and visualizing the evolution of a research field: A practical application to the Fuzzy Sets Theory field," Journal of Infometrics, pp. 146-166, 2010.

[17] M. Callon, J. ,. P. Courtial and F. Laville, "Co-word analysis as a tool for describing the network of interactions between basic and technological research: The case of polymer chemsitry," Scientometrics, pp. 155-205, 1991.

[18] M. Th, J. Boyd and O. Noorshams, "Automating Mouse Weighing In Group Homecages With Raspberry Pi Micro-Computers.," Journal of Neuroscience Methods, vol. 285, 2017.

[19] Automated Task Training And Longitudinal Monitoring Of Mouse Mesoscale Cortical Circuits Using Home Cages.. 
[20] F. Bolaños, J. LeDue and T. Murphy, "Cost effective raspberry pi-based radio frequency identification tagging of mice suitable for automated in vivo imaging," Journal of Neuroscience Methods, vol. 276, 2016.

[21] D. J. Ardesch, M. Balbi and T. Murphy, "Automated Touch Sensing In The Mouse Tapered Beam Test Using Raspberry Pi.," Journal of Neuroscience Methods, vol. 291, 2017.

[22] D. J. Boyd, H. Murphy, Timothy, H. ,. S. ,. B. ,. F. Scott and G. Silasi, "Individualized Tracking Of Self-Directed Motor Learning In GroupHoused Mice Performing A Skilled Lever Positioning Task In The Home Cage.," Journal of Neurophysiology, vol. 119, no. 1, pp. 337-346, 2018.
[23] S. McGill and D. Barker, "Comparison Of The Protein-Coding Genomes Of Three Deep-Sea, Sulfur-Oxidising Bacteria: "Candidatus Ruthia Magnifica", "Candidatus Vesicomyosocius Okutanii" And Thiomicrospira Crunogena.," BMC Research Notes, vol. 10, 2017.

[24] F. R. James and B. Daniel, "Comparison of the protein-coding gene content of Chlamydia trachomatis and Protochlamydia amoebophila using a Raspberry Pi computer," BMC Res Notes, vol. 8, 2015.

[25] D. Barker, D. Ferrier, P. Holland, J. Mitchell, H. Plaisier, M. Ritchie and

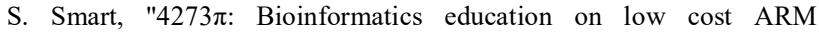
hardware," BMC bioinformatics, vol. 14, 2013.

[26] J. McDonagh, D. Barker and R. G. Alderson, "Bringing computational science to public," SpringerPlus, vol. 5, no. 259, 2016. 